\title{
Perbandingan Penggunaan Masker Anestesi Berpewangi dengan Masker Anestesi Tidak Berpewangi terhadap Tingkat Kecemasan Anak pada Induksi Inhalasi
}

\author{
Deni Nugraha, Dewi Yulianti Bisri, Radian Ahmad Halimi \\ Departemen Anestesiologi dan Terapi Intensif \\ Fakultas Kedokteran Universitas Padjadjaran/RSUP Dr. Hasan Sadikin Bandung
}

\begin{abstract}
Abstrak
Induksi inhalasi dapat memberikan pengalaman emosi yang traumatis terhadap anak seperti perasaan terkekang atau tercekik selama bernapas melalui masker dan bau yang tajam dari gas anestesi. Salah satu pendekatan nonfarmakologis yang dapat dilakukan adalah menggunakan masker beraroma buah-buahan sebelum induksi. Modifikasi sederhana dengan mengoleskan lip balm dengan wangi buah pada permukaan dalam masker anestesi merupakan salah satu pendekatan yang efektif dan murah. Tujuan penelitian ini adalah mengetahui perbandingan pengaruh penggunaan masker anestesi berpewangi dibanding dengan masker anestesi tidak berpewangi terhadap tingkat kecemasan anak pada induksi inhalasi. Penelitian dilakukan menggunakan metode uji klinis acak terkontrol buta tunggal secara prospektif terhadap 38 anak berusia 4-12 tahun yang menjalani anestesi umum dengan status fisik american society of anesthesiologist (ASA) I-II di RSUP Dr. Hasan Sadikin Bandung. Subjek dibagi menjadi dua kelompok, yaitu kelompok yang mendapat masker berpewangi dan kelompok yang mendapat masker tidak berpewangi. Tingkat kecemasan anak di ruang persiapan dan kamar operasi dinilai menggunakan skala modified yale preoperative anxiety scale (MYPAS). Skala MYPAS adalah baku emas untuk evaluasi kecemasan anak yang terdiri atas 22 penilaian dalam 5 kategori dengan realibilitas dan validitas tinggi. Analisis statistik dengan Uji Mann-Whitney. Tingkat kecemasan anak pada kelompok masker berpewangi secara bermakna lebih rendah dibanding dengan kelompok masker tidak berpewangi $(\mathrm{p}=0,000)$, namun penilaian di ruang persiapan tidak menunjukkan hasil yang bermakna $(\mathrm{p}=0,07)$. Kesimpulan penelitian adalah penggunaan masker anestesi berpewangi pada induksi inhalasi menghasilkan tingkat kecemasan anak yang lebih rendah dibanding dengan penggunaan masker anestesi tidak berpewangi.
\end{abstract}

Kata kunci: Anestesi pediatrik, induksi anestesi, induksi inhalasi, masker anestesi, masker berpewangi

\section{Comparison of between the Use of Scented Anesthetic Mask and Unscented Anesthetic Mask on Anxiety Level in Children during Inhalation Induction}

\begin{abstract}
Inhalation induction may be a traumatic emotional experience in children as they may feel restricted or suffocated while breathing through the mask and inhaling the sharp smell of the anesthetic gas. A nonpharmacological approach that may be applied include the use of fruit scented masks before induction. This simple modification is done by smearing fruit scented lip balm on the anesthetic mask surface, which is an effective and inexpensive approach. This study aimed to compare the effects of scented anesthetic masks and non-scented masks on child anxiety level during inhalation induction. This was a single blind prospective randomized controlled trial on 38 children aged 4-12 years old underwent general anesthesia with a physical American Society of Anesthesiologist (ASA) status I-II in Dr. Hasan Sadikin General Hospital Bandung. Subjects were divided into two groups: scented mask group and unscented mask group. The anxiety levels in the preparation room and the operating room were measured using the Modified Yale Preoperative Anxiety Scale (MYPAS). MYPAS is the gold standard for evaluating anxiety in children, made up of 22 ratings in 5 categories with high reliability and validity. Statistical analysis was performed using the Mann-Whitney test. The anxiety level in the scented mask group were found to be significantly lower when compared to the unscented group $(\mathrm{p}=0.000)$ but the evaluation in the preparation room did not show statistically significant results $(\mathrm{p}=0.07)$. This study concludes that the use of scented anesthetic masks in inhaled induction results in lower anxiety levels in children.
\end{abstract}

Keywords: Anesthetic induction, anesthetic mask, inhalation induction, pediatric anesthesia, scented mask

Korespondensi: Deni Nugraha, dr., Departemen Anestesiologi dan Terapi Intensi Fakultas Kedokteran Universitas Padjadjaran/RSUP Dr. Hasan Sadikin Bandung, Jl. Pasteur No. 38 Bandung 40161, Tlpn 022 2038285, Email deninugraha3711@gmail.com 


\section{Pendahuluan}

Kecemasan preoperatif pada anak merupakan masalah signifikan yang perlu ditangani dengan baik karena dapat menimbulkan stres pada anak, orangtua, maupun staf yang terlibat dalam operasi.1,2 Salah satu titik terjadi stres pada anak yang berkaitan dengan kecemasan adalah saat dilakukan prosedur induksi anestesi. Kecemasan saat induksi anestesi berhubungan dengan efek samping pascaoperasi seperti emergence delirium, peningkatan kebutuhan analgetik, perubahan perilaku, gangguan tidur, dan penurunan nafsu makan. Induksi anestesi pada sebagian besar anak dapat menjadi keadaan dengan tingkat ketegangan yang tinggi. ${ }^{1,3,4}$

Kecemasan pada anak selama periode perioperatif terjadi lebih dari $60 \%$ anak. Kecemasan preoperatif menyebabkan efek samping negatif pascaoperasi. Sebanyak 54\% anak menunjukkan perubahan perilaku negatif 2 minggu setelah operasi, $20 \%$ anak menunjukkan perubahan perilaku negatif berlanjut selama 6 bulan setelah operasi, dan $7 \%$ anak dengan perubahan perilaku negatif bertahan sampai 1 tahun setelah operasi..$^{1,3,4}$

Induksiinhalasi padaanakdipertimbangkan lebih bersahabat dibanding dengan induksi intravena sehingga induksi inhalasi menjadi pilihan dalam teknik pembiusan pada anak. Sisi negatif teknik induksi inhalasi dapat memberikan pengalaman emosi yang traumatis seperti perasaan terkekang atau tercekik selama bernapas melalui masker dan bau yang tajam dari gas anestesi. Bau yang tajam dari gas anestesi merupakan aspek yang paling sering menyebabkan keadaan tidak nyaman saat induksi sehingga anak merasa tegang karena bau tersebut. Selain itu, bau gas anestesi menyebabkan anak menjadi tidak kooperatif dan mask phobia. ${ }^{4-6}$

Berbagai intervensi dapat digunakan untuk mengatasi kecemasan preoperatif pada anak baik secara farmakologis dan nonfarmakologis. Pendekatan farmakologis memang terbukti efektif dalam mengurangi kecemasan pada anak, namun pendekatan farmakologis dapat menimbulkan beberapa efek samping seperti depresi sistem pernapasan, gelisah, agitasi, iritasi pada tempat pemberian (intranasal) dan memicu alergi yang tidak diketahui sebelumnya. ${ }^{7}$ Pendekatan nonfarmakologis seperti kehadiran orangtua selama induksi kadang tidak dapat diaplikasikan di beberapa rumah sakit. Pendekatan nonfarmakologis alternatif yang dapat dilakukan adalah dengan menggunakan masker beraroma buah-buahan sebelum dilakukan induksi anestesi. ${ }^{1,8}$

Penambahan wangi ekstrak buah ke dalam masker anestesi telah menunjukkan peningkatan penerimaan dan kepatuhan anak saat dilakukan induksi anestesi umum inhalasi. ${ }^{9}$ Penggunaan wewangian buah akan menyebabkan sistem saraf kranial olfaktorius terstimulasi yang kemudian diteruskan menuju bulbus olfaktorius yang berbatasan dengan sistem limbik untuk memengaruhi ingatan, emosi, dan perasaan seseorang. ${ }^{10}$

Penggunaan lip balm yang dioleskan pada permukaan dalam masker anestesi untuk menambahkan wangi buah telah dilakukan. Pengolesan lip balm dengan wangi buah tersebut memberikan wangi yang kuat, setelah digunakan masker tersebut dapat dicuci dengan detergen dan air sehingga dapat dipakai kembali. ${ }^{9}$

Tujuan penelitian ini adalah mengkaji penggunaan masker anestesi berpewangi dibanding dengan masker anestesi tidak berpewangi terhadap tingkat kecemasan anak pada induksi inhalasi.

\section{Subjek dan Metode}

Penelitian ini merupakan penelitian eksperimental yang dilakukan secara prospektif dengan melakukan uji klinis acak terkontrol buta tunggal (RCT single blind). Subjek penelitian ini adalah pasien anak yang menjalani operasi dengan induksi inhalasi di RSUP Dr. Hasan Sadikin Bandung yang memenuhi kriteria inklusi berupa status fisik American Society of Anesthesiologists (ASA) I-II, usia 4-12 tahun, dan belum terpasang infus. Kriteria eksklusi adalah pasien yang memerlukan premedikasi farmakologi perioperatif, tidak mampu mendengar dan 
melihat, memiliki riwayat alergi terhadap agen pewangi, dan memiliki riwayat anestesi sebelumnya. Kriteria pengeluaran adalah pasien yang tidak menghirup masker anestesi yang telah dilapisi lip balm selama 10 menit.

Penentuan besar sampel dilakukan berdasar atas perhitungan perbedaan 2 rerata dengan taraf kepercayaan 95\%, kuasa uji (power test) 80\% dan didapatkan jumlah sampel minimal untuk tiap kelompok adalah 19 orang. Pengambilan sampel dilakukan secara consecutive sampling dan alokasi subjek ke dalam salah satu kelompok dilakukan secara random blok permutasi.

Penelitian dilakukan di RSUP Dr. Hasan Sadikin Bandung pada 18 Juni hingga 30 November 2020 setelah mendapatkan persetujuan dari Komite Etik Penelitian Kesehatan Rumah sakit Dr. Hasan Sadikin Bandung/Fakultas Kedokteran Universitas Padjadjaran No: LB.02.01/X.6.5/138/2020. Peserta penelitian yang memenuhi kriteria inklusi dan tidak termasuk kriteria eksklusi diberikan penjelasan mengenai prosedur penelitian serta menandatangani persetujuan (informed consent) pada saat praoperasi. Subjek penelitian dibagi menjadi 2 kelompok, yaitu kelompok I yang mendapat masker berpewangi dan kelompok II yang mendapat masker tidak berpewangi. Satu hari sebelum operasi dilakukan kunjungan preoperasi untuk menilai tingkat kecemasan menggunakan skala MYPAS.

Sebelum operasi, kelompok I disediakan beberapa lip balm dengan wangi stroberi, jeruk, ceri, rose, dan cokelat. Pasien memilih lip balm dengan menciumnya, kemudian lip balm dioleskan ke bagian dalam masker anestesi sepanjang $1 \mathrm{~cm}$ secara merata. Kelompok II mendapat masker anestesi yang dioleskan lip balm tidak berpewangi. Pasien diminta menghirup wangi pada masker anestesi selama 10 menit di ruang persiapan dan dilakukan perekaman oleh tim peneliti. Pasien kemudian dipindahkan ke ruang operasi dan dilakukan induksi inhalasi dengan masker anestesi yang telah dilapisi lip balm yang sama sambil dilakukan perekaman oleh tim peneliti. Video rekaman pasien di ruang persiapan dan operasi diubah menjadi video hitam putih dan dinilai oleh empat residen anestesi yang telah diberikan penjelasan sehingga memiliki pemahaman seragam untuk menilai tingkat kecemasam menggunakan skala MYPAS.

Analisis statistik untuk data deskriptif ditampilkan dalam bentuk distribusi frekuensi dan persentase. Analisis data numerik dilakukan dengan Uji Normalitas ShapiroWilk dan dianalis menggunakan uji t tidak berpasangan dan Uji Mann-Whitney sesuai distribusi data. Analisis data ordinal dilakukan Uji Mann-Whitney dan analisis data kategorik menggunakan uji chi-square. Pengolahan data menggunakan software statistical product

Tabel 1 Perbandingan Karakteristik Subjek Penelitian antara Kedua Kelompok

\begin{tabular}{lccc}
\hline \multirow{2}{*}{ Variabel } & Masker Berpewangi & Masker Tidak Berpewangi & \multirow{2}{*}{ Nilai p } \\
\cline { 2 - 4 } & (n=19) & $7,63 \pm 2,67$ & 0,075 \\
\hline Usia (tahun), mean \pm SD & $9,16 \pm 2,59$ & & \\
Status ASA, n & & 4 & 0,461 \\
1 & 6 & 15 & \\
2 & 13 & & 1,000 \\
Tingkat kecemasan, n (\%) & 17 & 17 & \\
Tidak cemas & 2 & 2 & \\
Cemas ringan & 0 & 0 & \\
Cemas sedang & 0 & 0 & \\
Cemas berat & & & \\
\hline
\end{tabular}

Keterangan: Nilai pada variabel usia berupa Mean \pm SD, sedangkan Status ASA berupa frekuensi dan persentase. Nilai p pada variabel usia diperoleh dari Uji Mann Whitney (data tidak berdistribusi normal), sedangkan pada ASA dari uji chi square continue correction. Perbedaan bermakna jika $\mathrm{p}<0,05$ 
Tabel 2 Perbandingan Tingkat Kecemasan Anak di Ruang Persiapan Menggunakan Skala MYPAS antara Kelompok Masker Berpewangi dan Kelompok Masker Tidak Berpewangi

\begin{tabular}{lccc}
\hline \multirow{2}{*}{ Cemas } & Masker Berpewangi & Masker Tidak Berpewangi & \multirow{2}{*}{ Nilai $\mathbf{p}$} \\
\cline { 2 - 4 } & $\mathbf{n = 1 9}$ & $\mathbf{n = 1 9}$ & 0,070 \\
\hline Tidak, $\mathrm{n}$ & 9 & 4 & \\
Ringan, $\mathrm{n}$ & 10 & 12 & \\
Sedang, $\mathrm{n}$ & 0 & 1 & \\
Berat, $\mathrm{n}$ & 0 & 2 & \\
\hline
\end{tabular}

Keterangan: Nilai yang disajikan berupa frekuensi dan persentase. Nilai p dari Uji Mann Whitney (tidak memenuhi syarat pada uji Chi Square), perbedaan bermakna jika p $<0,05$

and service solution (SPSS) versi 24.0 untuk windows.

\section{Hasil}

Hasil analisis statistika menunjukkan bahwa karakteristik subjek penelitian menurut usia, status fisik ASA, dan tingkat kecemasan awal antara kedua kelompok tidak berbeda bermakna ( $p>0,05$; Tabel 1$)$.

Tingkat kecemasan anak di ruang persiapan pada kelompok masker berpewangi lebih ringan dibanding dengan kelompok masker tidak berpewangi, namun secara statistik tidak bermakna ( $p>0,05$; Tabel 2). Pada saat induksi inhalasi, tingkat kecemasan anak pada kelompok masker berpewangi lebih rendah dibanding dengan kelompok masker tidak berpewangi dengan perbedaan yang bermakna secara statistik ( $p<0,05$; Tabel 3$)$.

\section{Pembahasan}

Subjek pada penelitian ini terdiri atas 38 anak berusia 4-12 tahun dengan status fisik ASA I dan II yang belum terpasang infus dan menjalani operasi elektif dalam anestesi umum. Analisis kriteria umum pada subjek penelitian ini berdasar atas usia, status fisik ASA, dan tingkat kecemasan tidak berbeda bermakna antara kedua kelompok $(p>0,05)$ sehingga dapat disimpulkan bahwa kedua kelompok penelitian homogen dan layak dibandingkan.

Pada penelitian ini didapatkan tingkat kecemasan antara kelompok subjek yang mendapat masker berpewangi dan tidak berpewangi di ruang persiapan operasi tidak berbeda bermakna secara statistik $(p>0,05)$. Hal ini disebabkan oleh periode menunggu dan induksi anestesi adalah periode yang dinamis dengan tingkat kecemasan yang

Tabel 3 Perbandingan Tingkat Kecemasan Anak Saat Induksi Inhalasi Menggunakan Skala MYPAS antara Kelompok Masker Berpewangi dan Kelompok Masker Tidak Berpewangi

\begin{tabular}{lccc}
\hline \multirow{2}{*}{ Cemas } & Masker Berpewangi & Masker Tidak Berpewangi & \multirow{2}{*}{ Nilai p } \\
\cline { 2 - 4 } & $\mathbf{n = 1 9}$ & $\mathbf{n = 1 9}$ & $0,000^{*}$ \\
\hline Tidak, $\mathrm{n}$ & 3 & 1 & \\
Ringan, $\mathrm{n}$ & 15 & 14 & \\
Sedang, $\mathrm{n}$ & 1 & 3 & \\
Berat, $\mathrm{n}$ & 0 & 1 & \\
\hline
\end{tabular}

Keterangan: Nilai yang disajikan berupa frekuensi dan persentase. Nilai p dari Uji Mann Whitney (tidak memenuhi syarat pada uji Chi Square), perbedaan bermakna jika $\mathrm{p}<0,05$ 
bervariasi dari waktu-ke-waktu, bergantung pada kejadian dan interaksi anak dengan lingkungan. Saat berada di ruang persiapan, tingkat kecemasan anak cenderung lebih rendah karena tidak terdapat alat-alat medis pada jangkauan penglihatan anak, tidak ada suara mesin monitoring, dan tidak ada tenaga medis dengan baju operasi yang asing seperti di ruang operasi. ${ }^{5}$

Tingkat kecemasan saat induksi inhalasi cenderung meningkat dibanding dengan saat di ruang persiapan operasi. Hal ini sesuai dengan penelitian sebelumnya yang menyatakan bahwa induksi inhalasi menyebabkan peningkatan kecemasan pada anak yang secara bertahap semakin meningkat pada saat anak berpisah dengan orangtuanya dan mencapai puncaknya saat pemakaian masker anestesi di wajah anak. ${ }^{11} \mathrm{Hal}$ ini disebabkan oleh saat induksi inhalasi, anak berada di lingkungan kamar operasi yang tidak familiar, banyak orang yang mengenakan masker dan baju operasi yang tidak biasa, terdapat jarum dan spuit yang dilihat oleh anak, dan terpasang monitor yang menyebabkan anak panik dan cemas. ${ }^{5,12}$

Tingkat kecemasan kelompok subjek yang mendapat masker berpewangi lebih rendah dibanding dengan kelompok anak yang mendapat masker tidak berpewangi dengan perbedaan yang bermakna secara statistik dengan tiga subjek mengalami cemas berat. Hasil ini sejalan dengan penelitian sebelumnya yang menemukan perbedaan bermakna pada tingkat kecemasan subjek saat induksi inhalasi pada kelompok anak yang mendapat masker berpewangi dibanding dengan kelompok anak yang mendapat masker tidak berpewangi. Pengolesan lip balm dengan wangi buah memberikan wangi yang kuat sehingga dapat menstimulasi sistem saraf kranial olfaktorius yang kemudian diteruskan ke bulbus olfaktorius yang berbatasan dengan sistem limbik untuk memengaruhi ingatan, emosi, dan perasaan anak. Hal ini menyebabkan pelepasan neurohormon endorfin dan serotonin. Endorfin berikatan dengan reseptor opioid subtipe mu di sinaps ujung saraf dan menghambat pelepasan substansi $P$ yang berperan dalam transmisi nyeri sehingga dapat menghilangkan rasa sakit. Serotonin adalah neurotransmiter yang bekerja di sistem saraf pusat dalam mengontrol emosi, menimbulkan rasa senang, dan menghilangkan kecemasan. $5,10,12,13$

Kekurangan penelitian ini adalah penelitian tidak dilakukan dengan metode double blind yang merupakan baku emas untuk uji klinis terandomisasi. Penilaian subjek dari tim penilai menggunakan metode blinding dengan cara video hitam putih sehingga penilai tidak dapat menilai apakah lip balm yang dioles memiliki wangi atau tidak, sedangkan blinding pada subjek penelitian tidak dapat dilakukan karena perlakuan yang diterima (masker berpewangi) dapat dicium dan dikenali langsung oleh subjek penelitian.

\section{Simpulan}

Berdasar atas hasil penelitian dan pembahasan di atas maka dapat ditarik simpulan bahwa pemakaian masker anestesi berpewangi dapat menurunkan tingkat kecemasan anak saat induksi inhalasi. Penggunaan masker berpewangi dengan aplikasi lip balm pada masker dapat menjadi pilihan dibandingkan dengan masker komersil berpewangi karena harga yang lebih murah dan tidak mengandung alkohol etil.

\section{Daftar Pustaka}

1. O’Sullivan M, Wong GK. Preinduction techniques to relieve anxiety in children undergoing general anesthesia. Anesth Crit Care Pain. 2013;13(6):196-9.

2. Davidson AJ, Shrivastava PP, Jamsen K, Huang GH, Czarnecki C, Gibson MA, dkk. Risk factors for anxiety at induction of anesthesia in children: a prospective cohort study. Paediatr Anaesth. 2012;16(9):91927.

3. Kumar Kar S, Ganguly T. Preoperative anxiety in pediatric population: anesthesiologist"s nightmare. Translational Biomed. 2015;6(4):30.

4. Zielinska M, Holtby H, Wolf A. Pro- 
con debate: intravenous vs inhalation induction of anesthesia in children. Paediatr Anaesth. 2012;21(2):159-68.

5. Gupta A, Mathew PJ, Bhardwaj N. Flavored anesthetic masks for inhalational induction in children. Indian J Ped. 2017;84(10):73944.

6. Varughese AM, Nick TG, Gunter J, Wang Y, Kurth CD. Factors predictive of poor behavioral compliance during inhaled induction in children. Anesth Analg. 2013;107(2):413-21.

7. Dave NM. Premedication and Induction of Anaesthesia in paediatric patients. Indian J Anaesth. 2019;63(9):713-20.

8. Lewis RP, Jones RMJ, Estley JR, Wandless GJ. 'Fruit-flavored' mask for isofluranic induction inchildren. Anaesthesia. 2012;43:1052-4.

9. Walpole R, Barbour F, Aldridge LM. Lip balm: a novel way to 'flavour' facemasks for inhalation induction. Anaesthesia. 2013;56:97.
10. Matsumoto T, Asakura $\mathrm{H}$, Hayashi $\mathrm{T}$. Effects of olfactory stimulation from the fragrance of the Japanese citrus fruit yuzu (Citrus junos Sieb. ex Tanaka) on mood states and salivary chromogranin a as an endocrinologic stress marker. J Alternative Complementary Med. 2014;20(6):500-6.

11. Sadeghi A, Khaleghnajed A. Impact of parental presence during induction of anesthesia on anxiety level among pediartic patiens and their parents: a randomized clinical trial. Neuropsychiatric Dis Treat. 2017;12:3237-41.

12. Kain ZN, Mayes LC, Cicchetti DV, Bagnall AL, Finley JD, Hofstadter MB. The Yale properative anxiety scale: how does it compare with a "gold standard"?. Anesth Analg. 2013;85:783-8.

13. Astuti W, Setyowati H, Wijayanti K. Pengaruh aromaterapi bitter orange terhadap nyeri dan kecemasan fase aktif kala $I$. The $2^{\text {nd }}$ University research coloquium. 2015;1(1):371-82. 